\title{
Absorção e redistribuição de boro em coqueiro-anão-verde
}

\author{
Leandro Glaydson da Rocha Pinho(1), Pedro Henrique Monnerat ${ }^{(2)}$, André Assis Pires ${ }^{(1)}$ \\ e Anselmo Lúcio Aroucha Santos ${ }^{(3)}$
}

\begin{abstract}
(1)Escola Agrotécnica Federal de Colatina, BR 259, Km 70, CEP 29709910 Colatina, ES. E-mail: leandrogrpinho@hotmail.com, andre@eafcol.gov.br (2) Universidade Estadual do Norte Fluminense, Laboratório de Fitotecnia, Avenida Alberto Lamego, o 2000, CEP $28013-600$ Campos dos Goytacazes, RJ. E-mail: monnerat@uenf.br ${ }^{(3)}$ Escola Agrotécnica Federal de Satuba, Avenida 17 de agosto, s/nํㅡ, CEP 57120-000 Satuba, AL. E-mail: alsantos@click21.com.br
\end{abstract}

Resumo - O objetivo deste trabalho foi verificar se ocorre redistribuição de boro em coqueiros (Cocos nucifera), quando a aplicação de ácido bórico é realizada na axila foliar ou no solo. Foram empregados os seguintes tratamentos com ácido bórico: $30 \mathrm{~g}$ aplicados sobre a axila da folha número 10; $60 \mathrm{~g}$ aplicados ao solo; e controle, sem aplicação. Foram realizadas duas aplicações de B, com um intervalo de cinco meses entre elas. A unidade experimental consistiu de duas plantas, com seis repetições, em delineamento inteiramente casualizado. Foram determinados os teores de boro nas folhas 2, 6, 10,14 e 18, aos dois e quatro meses após a primeira aplicação de ácido bórico, e aos dois e cinco meses após a segunda aplicação. O boro se redistribuiu pela planta de coqueiro, independentemente da forma de aplicação. A elevação do teor de boro nas folhas persistiu por mais tempo, quando a aplicação de ácido bórico foi feita ao solo. As doses de ácido bórico aplicadas não causaram fitotoxidade, mesmo quando a aplicação foi repetida após um curto período.

Termos para indexação: Cocos nucifera, filotaxia do coqueiro, micronutriente, nutrição mineral, translocação de boro.

\section{Boron absorption and redistribution in green dwarf coconut tree}

\begin{abstract}
The aim of this work was to verify if boron redistribution occurs among the coconut palm (Cocos nucifera) fronds, when boric acid is applied on frond axils or on soil. The treatments with boric acid were: $30 \mathrm{~g}$ applied on the axil of frond number $10 ; 60 \mathrm{~g}$ applied to the soil; and a control without boric acid application. The B applications were repeated after five-month interval. The experimental unit consisted of two plants, with six replicates, in a randomized complete block design. Boron contents were determined in fronds number 2 , $6,10,14$ and 18, two and four months after the first boric acid application, and two and five months after the second application. Boron was redistributed in coconut plants, regardless of the application form. Increases in boron concentration in fronds persisted longer when boric acid was applied to the soil. The applied doses of boric acid had no phytotoxity effect, even when the application was repeated after five months.
\end{abstract}

Index terms: Cocos nucifera, coconut palm phyllotaxy, micronutrient, mineral nutrition, boron translocation.

\section{Introdução}

O cultivo de coqueiro-anão-verde tem-se expandido no Brasil e alcançando regiões mais centrais do País (Jucá et al., 2002; Ramos et al., 2004). Porém, as áreas plantadas são constituídas predominantemente por solos arenosos e, conseqüentemente, com baixa fertilidade natural (Fontes et al., 1998).

Santos et al. (2003) observaram que a aplicação de boro em coqueiros jovens promove a emissão de folhas normais, porém não corrige o sintoma em folhas já afetadas pela deficiência de boro. Assim, para se reduzir possíveis quedas na produtividade, o manejo da adubação com boro deve ser realizado para prevenir a deficiência e evitar a formação de folhas anormais.
A deficiência de boro em coqueiro, na região norte do Estado do Rio de Janeiro, foi constatada por Mirisola Filho (1997) e por Santos et al. (2003). Para a correção dessa deficiência, recomenda-se a aplicação de $30 \mathrm{~g}$ de bórax na axila (espaço entre a bainha e o estipe) da folha 4, em plantas jovens. Em plantas adultas, o bórax pode ser misturado com outros fertilizantes e aplicado ao solo (Sobral, 1998). Santos et al. (2003) verificaram que o fornecimento de $30 \mathrm{~g}$ de bórax, dividido em duas aplicações de $15 \mathrm{~g}$, nas axilas das folhas 2, 3 e 4, promoveu a emissão de folhas normais em plantas de coqueiro-anão-verde que apresentavam epinastia e deformações nas folhas novas, sintomas atribuídos à deficiência de boro (Sobral, 1998; Macêdo et al., 1999; Broschat, 2005). 
A aplicação de fertilizantes na axila foliar de coqueiros, em fase de produção, é difícil e demorada, em razão do porte elevado das plantas. Ao se aplicar o fertilizante na axila de folhas novas, espera-se que, com a chuva, o boro seja dissolvido e distribuído para as folhas mais velhas do coqueiro (Santos et al., 2003). O coqueiro-anão emite, aproximadamente, uma folha por mês (Ramos et al., 2004), e as folhas são dispostas alternadamente formando um ângulo de aproximadamente 144 graus entre uma folha e a folha subseqüente. Portanto, como a filotaxia do coqueiro é em espiral (Frémond et al., 1966), e a bainha de uma folha recobre parte da bainha da folha imediatamente mais nova, o boro pode ser absorvido em várias axilas, mesmo quando aplicado em apenas uma axila foliar.

A deficiência de boro foi diagnosticada em coqueiros adultos (Macêdo et al., 1999) e, mesmo que se consiga aplicar boro no ponto de crescimento dessas plantas, se o boro for redistribuído pela planta, a aplicação na axila de folha mais velha pode ser mais fácil e prática.

O boro é um micronutriente considerado de baixa mobilidade no floema (Marschner, 1995; Dannel et al., 2000; Malavolta, 2006) da maioria das espécies. Entretanto, em espécies que apresentam produção apreciável de açúcares do tipo manitol, sorbitol, dulcitol e outros, o boro é considerado um micronutriente de mobilidade intermediária (Marschner, 1995). Em coqueiro, não foram encontrados dados sobre a produção desses açúcares. Contudo, Santos et al. (2003) observaram que o boro pode ser móvel nessa espécie.

Em solos de textura média a argilosa, a adsorção de boro pode ser a principal causa da deficiência. Fatores como o aumento do teor de matéria orgânica, do $\mathrm{pH}$ e do teor de óxidos de ferro e de alumínio influenciam na adsorção de boro ao solo; entretanto, até mesmo em pH menor que neutro ocorre adsorção (Valadares et al.,1998; Alleoni \& Camargo, 2000). Rosolem \& Bíscaro (2007) mostraram que a adsorção de boro é importante no ano em que se realiza a calagem, nos outros anos a adsorção diminui, o que faz com que maior teor do nutriente fique em solução.

Pinho (2004), por meio do fornecimento de ácido bórico em solo arenoso ena axila da folha 10 , conseguiu aumentar os teores de boro na folha 14 e elevar a produtividade de plantas adultas de coqueiro-anão-verde. Isso é uma evidência de que a lixiviação de boro no solo pode não ser um processo tão expressivo em regiões com baixos índices pluviométricos. Entretanto, até mesmo em solos argilosos, como o Latossolo Vermelho-Amarelo utilizado por Rosolem \& Bíscaro (2007), o aumento na percolação de água eleva a lixiviação de boro, em solos fertilizados ou não com o nutriente.

Apesar de a adubação com boro em coqueiro permitir a emissão de folhas normais (Santos et al., 2003) em plantas antes deficientes e aumentar a produtividade (Pinho, 2004), não se tem informações sobre a eficiência dos métodos de aplicação na redistribuição de boro entre as folhas de coqueiros, nem de doses máximas que poderiam ser aplicadas sem causar toxidez às plantas.

O objetivo deste trabalho foi verificar se ocorre a redistribuição de boro em coqueiros, quando a aplicação de ácido bórico é realizada na axila foliar ou no solo.

\section{Material e Métodos}

O experimento foi instalado na fazenda Taí Agropecuária, localizada no Município de Campos dos Goytacazes, Estado do Rio de Janeiro. As plantas, na data da instalação do experimento (6/5/2003), tinham aproximadamente cinco anos de idade. O solo da área experimental é classificado como Neossolo Quartzarênico (Embrapa, 2006). A área experimental representa bem as condições edafoclimáticas das áreas de cultivo do coqueiro-anão no norte Fluminense, que é uma das maiores regiões produtoras de coqueiro-anão-verde no Estado do Rio de Janeiro. O clima do município é caracterizado segundo a classificação de Köppen como Aw, quente e úmido, com estação chuvosa no verão e estiagem no inverno. A precipitação média anual é de $1.080 \mathrm{~mm}$ e a temperatura média anual situa-se entre 24 e $25^{\circ} \mathrm{C}$.

Antes da instalação do experimento, amostras de solo foram retiradas na linha de plantio, nas profundidades de 0-20, 20-40 e 40-60 cm (Tabelas 1 e 2). Os métodos analíticos utilizados estão descritos em Embrapa (1997) e Embrapa (1999), para as análises física e química, respectivamente.

Foi empregado o delineamento experimental inteiramente ao acaso, com seis repetições e duas plantas por unidade experimental. Os tratamentos constaram de duas formas de aplicação de ácido bórico (17\% de boro, em pó): $30 \mathrm{~g}$ por planta de $\mathrm{H}_{3} \mathrm{BO}_{3}$, na axila da folha 10 (Figura 1); 60 g por planta de $\mathrm{H}_{3} \mathrm{BO}_{3}$, aplicados ao solo; e um tratamento testemunha, sem 
aplicação de boro. As aplicações foram realizadas em $6 / 5$ e $3 / 10 / 2003$.

Foram amostradas as folhas 2, 6, 10, 14 e 18, aos dois e quatro meses após a primeira aplicação de ácido bórico, e aos dois e cinco meses após a segunda aplicação, retirando-se do centro das folhas $10 \mathrm{~cm}$ da parte mediana de seis folíolos, três de cada lado da folha. Em todas as amostragens, os folíolos foram acondicionados em sacos de papel tipo Kraft; no laboratório, passaram por limpeza com algodão embebido em água deionizada e, depois da retirada da nervura central, foram secados em estufa de circulação forçada de ar a $75^{\circ} \mathrm{C}$, durante 48 horas, moídos em moinho tipo Wiley, com peneira de 30 mesh, e acondicionados em recipientes hermeticamente fechados. Em todas as amostragens, foram submetidos $250 \mathrm{mg}$ do tecido vegetal à digestão seca, adicionando-se, em seguida, $10 \mathrm{~mL}$ de $\mathrm{HNO}_{3}$ (1:60) à cinza e, após homogeneização e centrifugação, determinou-se o teor de $\mathrm{B}$ no sobrenadante, pelo método da Azometina-H (Malavolta et al., 1997).

A área foi irrigada por microasperção e fertirrigada, diariamente, com uréia e cloreto de potássio, aplicandose $70 \%$ da recomendação da Embrapa (Sobral, 1998). O controle de ácaros foi realizado com a aplicação do acaricida Carbosulfan, e o controle de plantas daninhas com glifosato, na projeção da copa, e com roçadeira acoplada a um trator, nas entrelinhas.

As comparações entre os tratamentos de aplicação de ácido bórico foram feitas utilizando-se a análise de variância. Para aquelas variáveis em que o teste
F apresentou significância, a 5\% de probabilidade, utilizou-se o teste Tukey, também a $5 \%$ de probabilidade, para avaliação da diferença entre as médias dos tratamentos.

\section{Resultados e Discussão}

A aplicação de ácido bórico ao solo aumentou o teor de B em todas as folhas amostradas (Figura $2 \mathrm{~A}$ ). Quando o ácido bórico foi aplicado na axila da folha, inicialmente, apenas a folha 10 teve seu teor de B aumentado significativamente (Figura 2 A). Como o coqueiro emite aproximadamente uma folha por mês (Frémond et al., 1966; Ramos et al., 2004), essa folha 10, amostrada dois meses após a aplicação, era a folha 8 por ocasião da aplicação, e se situava ao lado e acima da folha que recebeu ácido bórico (Figura 1). Possivelmente, a folha 10 teve seu teor de boro aumentado em razão de sua proximidade com a folha que recebeu a aplicação, o que pode ter proporcionado o contato com ácido bórico adicionado, fato que não ocorreu com as outras folhas amostradas. A maior acumulação de boro nas folhas do coqueiro, quando a aplicação foi via solo, pode ter sido decorrente da maior dose de ácido bórico aplicada. Na primeira amostragem, os teores de boro nas folhas da testemunha foram relativamente altos (Figura $2 \mathrm{~A}$ ), possivelmente em razão de a amostragem ter sido realizada durante um período de temperatura média mais baixa e em dias mais curtos, o que contribuiu para menor taxa de crescimento das plantas Child (1964), e pode ter provocado o acúmulo de B nas folhas.

Tabela 1. Teores de $\mathrm{P}, \mathrm{K}, \mathrm{Ca}, \mathrm{Mg}, \mathrm{Al}, \mathrm{H}+\mathrm{Al}, \mathrm{Na}, \mathrm{C}$ e matéria orgânica e os valores de $\mathrm{pH}, \mathrm{SB}$, T, t, m e V do solo nas três profundidades (Prof.) amostradas ${ }^{(1)}$.

\begin{tabular}{|c|c|c|c|c|c|c|c|c|c|c|c|c|c|c|c|}
\hline $\begin{array}{l}\text { Prof. } \\
(\mathrm{cm})\end{array}$ & $\mathrm{pH}$ & $\begin{array}{c}\mathrm{P} \\
\left(\mathrm{mg} \mathrm{dm}^{-3}\right)\end{array}$ & \multirow{2}{*}{$\begin{array}{c}\mathrm{K} \\
-0 .- \\
\end{array}$} & \multirow{2}{*}{$\begin{array}{c}\mathrm{Ca} \\
11\end{array}$} & \multicolumn{2}{|c|}{$\begin{array}{cr}\mathrm{Mg} & \mathrm{Al} \\
-\left(\mathrm{mmol}_{\mathrm{c}} \mathrm{dm}^{-3}\right)\end{array}$} & $\mathrm{H}+\mathrm{Al}$ & $\mathrm{Na}$ & \multicolumn{2}{|c|}{$\begin{array}{c}\mathrm{C} \\
\mathrm{MO}\end{array}$} & \multicolumn{3}{|c|}{ 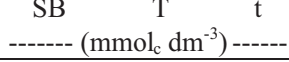 } & \multicolumn{2}{|c|}{ m $\frac{V}{}$} \\
\hline $0-20$ & 4,8 & 15,0 & & & 2,0 & 8,0 & 72 & 0,50 & 18,9 & 32,6 & 14,0 & 86,0 & 22,0 & 36 & 16 \\
\hline $20-40$ & 5,0 & 15,0 & 0,18 & 14 & 1,0 & 5,0 & 64 & 0,90 & 17,1 & 29,5 & 16,0 & 80,0 & 21,0 & 24 & 20 \\
\hline $40-60$ & 5,1 & 11,0 & 0,13 & 8 & 1,0 & 3,0 & 34 & 0,40 & 7,3 & 12,6 & 10,0 & 44,0 & 13,0 & 24 & 22 \\
\hline
\end{tabular}

${ }^{(1)} \mathrm{SB}$, soma de bases; T, CTC a pH 7; t, CTC efetiva; m, saturação por alumínio; V, saturação por bases; MO, matéria orgânica.

Tabela 2. Teores de B, Cu, Fe, Mn, Zn e S, valor da condutividade elétrica (CE) na pasta saturada e composição granulométrica do solo nas três profundidades (Prof.) amostradas.

\begin{tabular}{|c|c|c|c|c|c|c|c|c|c|c|c|c|c|}
\hline \multirow{3}{*}{$\begin{array}{l}\text { Prof. } \\
(\mathrm{cm})\end{array}$} & \multirow[t]{3}{*}{ B } & \multirow[t]{3}{*}{$\mathrm{Cu}$} & \multirow{2}{*}{$\mathrm{Fe}$} & \multirow{2}{*}{$\begin{array}{l}\mathrm{Mn} \\
\left.\mathrm{m}^{-3}\right)\end{array}$} & \multirow[t]{2}{*}{$\mathrm{Zn}$} & \multirow[t]{2}{*}{$\mathrm{S}$} & \multirow{3}{*}{$\begin{array}{c}\mathrm{CE} \\
\left(\mu \mathrm{S} \mathrm{cm}^{-1}\right)\end{array}$} & \multicolumn{4}{|c|}{ Areias } & \multicolumn{2}{|c|}{ Silte Argila } \\
\hline & & & & & & & & Grossa & Média & Fina & Total & ------- & -1) ----- \\
\hline & & & & & & & & ------ & 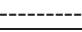 & $\left.g^{-1}\right)-$ & & & \\
\hline $0-20$ & 0,35 & 1,4 & 35 & 1,0 & 0,4 & 37,7 & 198 & 90 & 300 & 320 & 710 & 90 & 200 \\
\hline $20-40$ & 0,20 & 0,8 & 35 & 1,0 & 0,1 & 30,0 & 148 & 110 & 270 & 330 & 710 & 80 & 210 \\
\hline $40-60$ & 0,24 & 0,4 & 22 & 0,2 & 0,2 & 21,8 & 160 & 110 & 430 & 380 & 920 & 0 & 80 \\
\hline
\end{tabular}


$\mathrm{Na}$ segunda coleta, decorridos quatro meses da primeira aplicação de ácido bórico, todas as folhas amostradas das plantas fertilizadas com boro apresentaram teores mais elevados do micronutriente (Figura 2 B). No tratamento na axila foliar, todas as folhas apresentaram teores de boro superiores aos das plantas da testemunha, quais sejam as localizadas acima (folhas 2, 6 e 10), abaixo (folha 18) e no ponto de aplicação (folha 14, que era a folha 10 quatro meses antes) do ácido bórico na axila (Figura $2 \mathrm{~B}$ ). O teor de boro na folha 10 , no tratamento na axila foliar, não diferiu estatisticamente do teor encontrado na folha 10 das plantas que receberam a aplicação de ácido bórico no solo. A folha 10, na segunda coleta, era a folha 6 por ocasião da primeira aplicação de boro. Essa folha se localizava acima e no lado oposto à folha que recebeu boro em sua axila (Figura 1). Nesse caso, essa folha não entrou em contato direto com o boro adicionado. O teor de boro na folha 14, que era a folha que havia recebido boro quatro meses antes, encontrava-se próximo ao teor das folhas 10 e 18, situadas na face oposta do estipe (Figura 1). É necessário considerar que as bainhas das folhas mais novas encontram-se envolvidas parcialmente pelas bainhas das folhas mais velhas, de forma que, quando se aplica ácido bórico na bainha da folha 10, as bainhas das folhas 9 e 8 também podem ser atingidas, com o tempo.

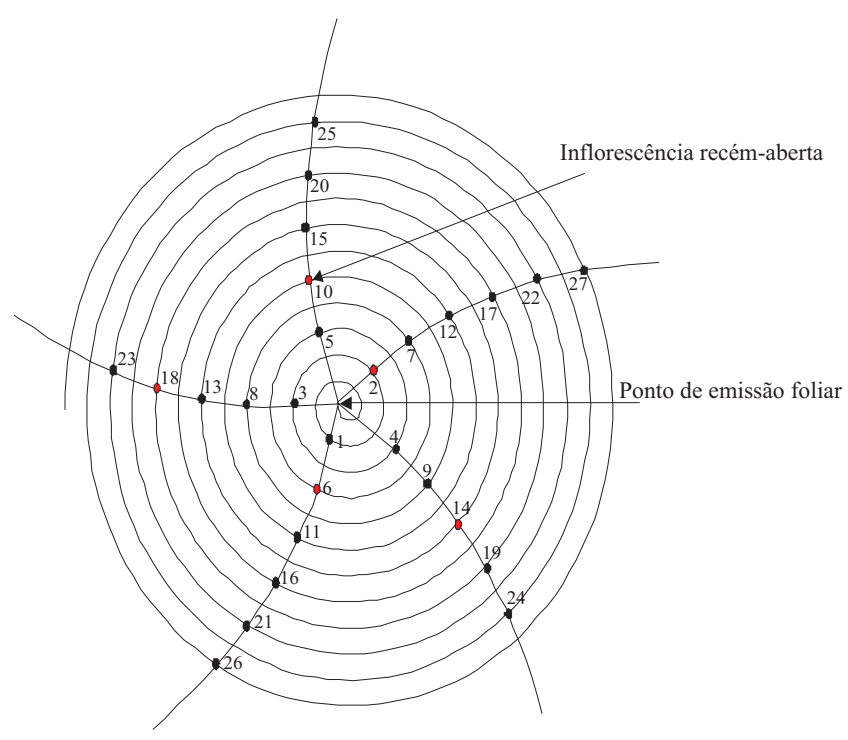

Figura 1. Posição esquemática das folhas do coqueiro no plano. Os pontos em vermelho representam as folhas amostradas. Adaptado de Frémond et al. (1966).
$\mathrm{Na}$ terceira coleta, efetuada dois meses após a segunda aplicação dos tratamentos, as folhas 6,10 e 14, das plantas que receberam aplicação ao solo, apresentaram teores de boro maiores que as mesmas folhas do tratamento na axila e que a testemunha. No tratamento na axila, a tendência de aumento do teor de boro nas folhas acima do ponto de aplicação continuou (Figura $2 \mathrm{C}$ ). Esses resultados e os observados após a primeira aplicação à axila são evidência de que o boro foi absorvido e redistribuído entre as folhas novas da planta. Ressalta-se que os sintomas de deficiência de boro ocorrem em folhas novas; assim, o fornecimento de boro, tanto no solo quanto na axila, resulta em correção dos sintomas nas folhas a serem emitidas (Sobral, 1998; Santos et al., 2003).

Os teores de boro nas folhas das plantas fertilizadas com ácido bórico não se elevaram suficientemente para causar toxidez, o que revela que o coqueiro pode ser adubado com boro em intervalos relativamente curtos. Pinho (2004) aplicou doses de ácido bórico de 80 e 40 g por planta no solo e na axila do coqueiro-anão-verde, respectivamente, em intervalos de quatro meses, e as plantas também não apresentaram sinais de toxidez. Trabalhos que tenham utilizado doses superiores a essas não foram encontrados na literatura.

$\mathrm{Na}$ quarta amostragem foliar, realizada cinco meses após a segunda aplicação de ácido bórico (Figura 2 D), os teores de boro nas plantas que receberam a aplicação ao solo foram, em geral, maiores que os obtidos nas plantas da testemunha e do tratamento na axila, o que revela um efeito mais persistente do boro aplicado ao solo. A lixiviação de boro tem sido apontada como uma das causas de deficiência de boro, principalmente em solos arenosos (Silva et al., 1995; Communar \& Keren, 2006), como o da área experimental (Tabela 2). Porém, a matéria orgânica, presente nas camadas superiores do solo (Tabela 1), pode ter complexado ou adsorvido parte do boro aplicado (Hatcher et al., 1967) e proporcionado, com o tempo, uma descomplexação ou dessorção, suficiente para atender a demanda da planta. A lixiviação de boro pode ocorrer (Silva et al., 1995; Rosolem \& Bíscaro, 2007), todavia é mais freqüente em solos arenosos, pobres em matéria orgânica e localizados em regiões chuvosas (Silva et al., 1995; Communar \& Keren, 2006). Segundo Yamada (2000), as razões para não se aplicar doses de boro maiores que as atualmente praticadas são duas: a estreita faixa entre a deficiência e a toxidez de boro na planta e a facilidade de 
lixiviação desse elemento. Contudo, essas razões têm sido questionadas (Correa et al., 1985; Chapman et al., 1997; Goldberg, 1997). Neste trabalho, a classe textural das camadas do solo de $0-20$ e $20-40 \mathrm{~cm}$ é classificada como franco arenosa, e a camada de 40-60 cm é arenosa. Neste tipo de solo, apesar da predominância de areia, a aplicação de boro no solo mostrou-se mais eficiente que a aplicação na axila foliar, o que indica que a lixiviação não deve ter ocorrido em grau apreciável.

$\mathrm{Na}$ quarta amostragem foliar, nas plantas que receberam ácido bórico na axila, somente as folhas 14 e 18 apresentaram teores de boro significativamente superiores aos observados na testemunha. A forte adsorção ou complexação do ácido bórico pelo material orgânico (Hatcher et al., 1967) presente na bainha do coqueiro pode ser uma das causas para o efeito menos persistente da aplicação de boro na axila foliar.
Quando as aplicações de ácido bórico são realizadas ao solo, espera-se uma distribuição de boro preferencial às folhas que mais transpiram na planta, as quais deveriam apresentar, portanto, maior teor (Figura 2 B, C e D). Observou-se, no entanto, que a folha 2 das plantas fertilizadas com boro no solo sempre apresentou teor de boro superior ao encontrado nas plantas testemunhas. Vale ressaltar que a folha 2 nas coletas 1 e 3 era a folha flecha na época das aplicações foliares, e a folha 2 nas coletas 2 e 4 não estava nem mesmo visível na época das aplicações foliares. Portanto, tecidos em formação, que pouco ou nada transpiram como os primórdios foliares, também tiveram sua demanda por boro atendida em ambas formas de aplicação de boro usadas neste trabalho. A absorção direta pela bainha das folhas envoltas pela bainha da folha 10, a entrada nos vasos do xilema do estipe e sua translocação para as folhas superiores pela corrente transpiratória e a translocação pelo floema são as possíveis explicações

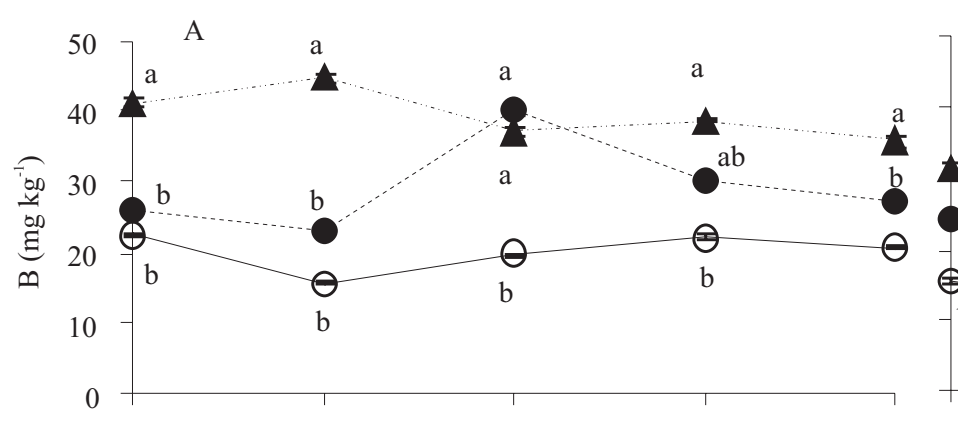

B
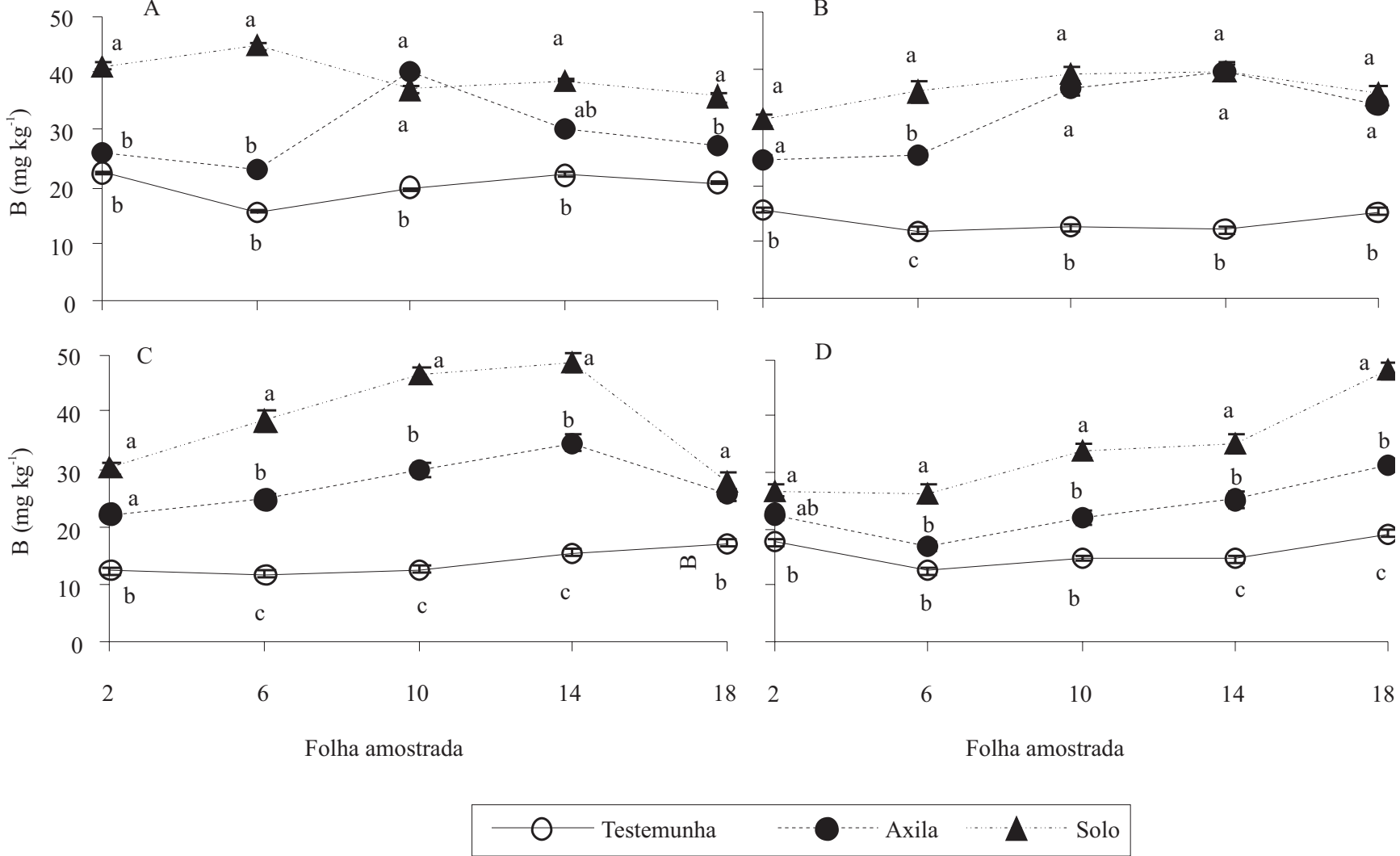

Figura 2. Teor de boro na matéria seca das folhas 2, 6, 10, 14 e 18 de coqueiro-anão-verde, em resposta às aplicações de ácido bórico na axila da folha 10 (30 g por planta) e no solo (60 g por planta). A e B, amostragens aos dois e quatro meses após a primeira aplicação; C e D, amostragens aos dois e cinco meses após a segunda aplicação, realizada cinco meses após a primeira. 
para que o boro aplicado à folha número 10 chegue às folhas acima. O carreamento do ácido bórico da bainha da folha 10 para a bainha de folhas inferiores e a translocação pelo floema são possibilidades sugeridas para o aumento observado no teor desse nutriente nas folhas inferiores às da aplicação.

O boro é um micronutriente caracterizado por apresentar mobilidade dependente da espécie, que é possível em razão da complexação do boro com açúcares e álcoois que possuem as hidroxilas na posição cis (Brown \& Hu, 1996; Hu et al., 1997). Em algumas fruteiras, como macieira, ameixeira, cerejeira (Brown \& Hu, 1998) e abacaxizeiro (Siebeneichler et al., 2005), o boro é móvel. Em coqueiro, Santos et al. (2003) aventaram essa possibilidade, que é corroborada pelos resultados observados neste trabalho.

\section{Conclusões}

1. A aplicação de boro ao solo é mais eficiente no fornecimento desse micronutriente às plantas, e seu efeito é mais persistente, quando comparado à aplicação na axila.

2. A aplicação de ácido bórico na axila da folha 10 promove rápido incremento no teor de boro em folhas localizadas acima e abaixo do ponto de aplicação, e, nas doses utilizadas, não causa fitotoxidez, nem mesmo quando a aplicação é repetida pouco tempo depois.

\section{Agradecimentos}

À Fundação Carlos Chagas Filho de Amparo à Pesquisa do Estado do Rio de Janeiro, pelo apoio financeiro.

\section{Referências}

ALLEONI, L.R.F.; CAMARGO, O.A. Boron adsorption in soils from the state of São Paulo, Brazil. Pesquisa Agropecuária Brasileira, v.35, p.413-421, 2000.

BROSCHAT, T.K. Boron Deficiency in Palms. University of Florida, Ifas Extension, 2005. Disponível em: <http://edis.ifas.ufl.edu/EP264>. Acesso em: out. 2008.

BROWN, P.H.; HU, H. Phloem boron mobility in diverse plant species. Botanical Acta, v.377, p.331-335, 1998.

BROWN, P.H.; HU, H. Phloem mobility of boron is species dependent: evidence for phloem mobility in sorbitol-rich species. Annals of Botany, v.77, p.497-505, 1996.

CHAPMAN, V.J.; EDWARDS, D.G.; BLAMEY, F.P.C.; ASHER, C.J. Challenging the dogma of a narrow supply range between deficiency and toxicity of boron. In: BELL, R.W.; RERKASEM, B. Boron in Soils and Plants. Dordrecht: Kluwer Academic Publishers, 1997. p.151-155.
CHILD, R. Coconuts. London: Longmans,1964. 215p.

COMMUNAR, G.; KEREN, R. Rate-limited boron transport in soils: the effect of soil texture and solution $\mathrm{pH}$. Soil Science Society of America Journal, v.70, p.882-892, 2006.

CORREA, A.E.; PAVAN, M.A.; MIYAZAWA, M. Aplicação de boro no solo e respostas do cafeeiro. Pesquisa Agropecuária Brasileira, v.20, p.177-181, 1985.

DANNEL, F.; PFEFFER, H.; RÖMHELD, V. Characterization of root boron pools, boron uptake and boron translocation in sunflower using the stable isotopes ${ }^{10} \mathrm{~B}$ and ${ }^{11} \mathrm{~B}$. Australian Journal of Plant Physiology, v.27, p.397-405, 2000.

EMBRAPA. Centro Nacional de Pesquisa de Solos. Manual de análises químicas de solos, plantas e fertilizantes. Rio de Janeiro: Embrapa Solos; Campinas: Embrapa Informática Agropecuária; Brasília, DF: Embrapa Comunicação para Transferência de Tecnologia, 1999.

EMBRAPA. Centro Nacional de Pesquisa do Solos. Manual de métodos de análises de solo. Rio de Janeiro: Embrapa-CNPS, 1997. 212p.

EMBRAPA. Centro Nacional de Pesquisa de Solos. Sistema Brasileiro de Classificação dos Solos. Rio de Janeiro: Embrapa Solos, 2006. 306p.

FONTES, H.R.; CINTRA, F.L.D.; CARVALHO FILHO, O.M. de. Implantação e manejo da cultura do coqueiro. In: FERREIRA, J.M.S.; WARWICK, D.R.N.; SIQUEIRA, L.A. A cultura do coqueiro no Brasil. Aracaju: Embrapa-SPI, 1998. p.99-128.

FRÉMOND, Y:; ZILLER, R.; NUCE DE LAMOTHE, M. de. The coconut palm. Berna: Instituto Internacional do Potássio, 1966. 222p.

GOLDBERG, S. Chemistry and mineralogy of boron in soils. In: GUPTA, U.C. Boron and its role in crop production. Boca Raton: CRC Press, 1997. p.3-44.

HATCHER, J.T.; BOWER, C.A.; CLARCK, M. Adsorption of boron by soils as influenced by hidroxy aluminum and surface area. Soil Science, v.104, p.422-426, 1967.

HU, H.; PENN, S.G.; LEBRILLA, C.B.; BROWN, P.H. Isolation and characterization of soluble boron complex in higher plantas. The mechanism of phloem mobility of boron. Plant Physiology, v.113, p.649-655, 1997.

JUCÁ, M.P.; GAÍVA, H.N.; PEREIRA, W.E.; MILESKI, A. Comportamento vegetativo de seis cultivares de coqueiro-anão (Cocos nucifera L.), em Santo Antônio de Leverger, MT. Revista Brasileira de Fruticultura, v.24, p.463-467, 2002.

MACÊDO, J.L.V. de; GASPAROTO, L.; CUNHA, R.N.V. da. Deficiência de boro em coqueiro: sintomas e correção. Manaus: Embrapa-CPAA, 1999. p.1-3. (Embrapa-CPAA. Instruções Técnicas, 4).

MALAVOLTA, E. Manual de Nutrição Mineral de Plantas. São Paulo: Editora Agronômica Ceres, 2006. v.1. 638p.

MALAVOLTA, E.; VITTI, G.C.; OLIVEIRA, S.A. Avaliação do estado nutricional das plantas. Piracicaba: Associação brasileira para pesquisa da potassa e do fosfato, 1997. 316p.

MARSCHNER, H. Mineral nutrition of higher plants. $2^{\text {nd }}$ ed. London: Academic Press, 1995. 889p.

MIRISOLA FILHO, L.A. Avaliação do estado nutricional do coqueiro anão (Cocos nucifera $\mathrm{L}$.) na região norte Fluminense. 
1997. 57p. Dissertação (Mestrado) - Universidade Estadual do Norte Fluminense Darcy Ribeiro, Campos dos Goytacazes.

PINHO, L.G. da R. Controle da mancha anelar dos frutos de coqueiro anão verde no noroeste do Estado do Rio de Janeiro: efeitos da aplicação de ácido bórico. 2004. 44p. Dissertação (Mestrado) - Universidade Estadual do Norte Fluminense Darcy Ribeiro, Campos dos Goytacazes.

QUAGGiO, J.A.; MATTOS JUNIOR, D.; CANTARELLA, H.; TANK JUNIOR, A. Fertilização com boro e zinco no solo em complementação à aplicação via foliar em laranjeira Pêra. Pesquisa Agropecuária Brasileira, v.38, p.627-634, 2003.

RAMOS, V.H.V.; PINTO, A.C.Q.; ARAGÃO, W.M.; GOMES, A.C.; JUNQUEIRA, N.T.V.; LOBATO, E.; OLIVEIRA, M.A.S. Comportamento de cultivares de coqueiros anão e híbridos no Distrito Federal. Revista Brasileira de Fruticultura, v.26, p.363-365, 2004.

ROSOLEM, C.A.; BÍSCARO, T. Adsorção e lixiviação de boro em Latossolo Vermelho-Amarelo. Pesquisa Agropecuária Brasileira, v.42, p.1473-1478, 2007.

SANTOS, A.L. dos; MONNERAT, P.H.; ALVES, E.A.B. Teor foliar de boro em função da aplicação de bórax na axila foliar de coqueiro anão verde no Norte Fluminense. Pesquisa Agropecuária e Desenvolvimento Sustentável, v.1, p.165-171, 2003.
SIEBENEICHLER, S.C.; MONNERAT, P.H.; CARVALHO, A.J.C. de; SILVA, J.A. da; MARTINS, A.O. Mobilidade do boro em plantas de abacaxi. Revista Brasileira de Fruticultura, v.27, p.292-294, 2005.

SILVA, N.M.; CARVALHO, L.H.; KONDO, J.I.; BATAGLIA, O.C.; ABREU, C.A. Dez anos de sucessivas adubações com boro no algodoeiro. Bragantia, v.54, p.177-185, 1995.

SOARES, A.M. Influência de nitrogênio, zinco e boro e de suas respectivas interações no desempenho da cultura do milho (Zea mays L.). 2003. 92p. Dissertação (Mestrado) - Escola Superior de Agricultura Luiz de Queiroz, Piracicaba.

SOBRAL, F.L. Nutrição e adubação do coqueiro. In: FERREIRA, J.M.S.; WARWICK, D.R.N.; SIQUEIRA, L.A. A cultura do coqueiro no Brasil. Aracaju: Embrapa-SPI, 1998. p.129-157.

VALLADARES, G.S.; PEREIRA, M.G.; ALVES, G.C. Aplicação de duas isotermas de adsorção de boro em solo de baixada do Estado do Rio de Janeiro. Revista Brasileira de Ciência do Solo, v.22, p.361-365, 1998.

YAMADA, T. Boro: será que estamos aplicando a dose suficiente para o adequado desenvolvimento das plantas? Informações Agronômicas, n.90, 2000.

Recebido em 28 de julho de 2008 e aprovado em 5 de novembro de 2008 